УДК 582.711.711: $577.13(571.6)$

\title{
ОПРЕДЕЛЕНИЕ ОПТИМАЛЬНЫХ УСЛОВИЙ ЭКСТРАКЦИИ ДЛЯ ИССЛЕДОВАНИЯ СОСТАВА ФЕНОЛЬНЫХ СОЕДИНЕНИЙ SPIRAEA BETULIFOLIA PALL. METOДOM ВЭЖX
}

\section{(C) В.А. Костикова}

\author{
Центральный сибирский ботанический сад СО РАН, ул. Золотодолинская, \\ 101, Новосибирск, 630090 (Россия), e-mail: serebryakova-va@yandex.ru
}

Проведены исследования по оптимизации условий экстракции фенольных соединений из листьев Spiraea betulifolia Pall. для дальнейшего фитохимического и хемотаксономического исследования методами высокоэффективной жидкостной хроматографии (ВЭЖХ). При планировании эксперимента в качестве переменных факторов были выбраны концентрация экстрагента (водные и водно-этанольные 20, 40, 50, 60, 70, 80 и 96\% извлечения) и масса навески сырья $(0,1,0,2,0,4,0,6,0,8$ и 1 г). Об эффективности экстракции судили по качественному составу фенольных веществ на ВЭЖХ-хроматограммах. Проведенные исследования показали, что для изучения состава фенольных соединений, содержащихся в листьях S. betulifolia, методом ВЭЖХ, следует использовать концентрированные экстракты, полученные из навески $0,1-1$ г с использованием 40-70\% водно-этанольных растворов. В листьях S. betulifolia методом ВЭЖХ выявлено 25 фенольных соединений, из которых идентифицированы хлорогеновая и $n$ кумаровая кислоты, дигидрокверцетин, кверцетин, кемпферол, рутин, гиперозид и астрагалин.

Ключевые слова: Spiraea betulifolia, экстракция, фенольные соединения, ВЭЖХ.

Исследование выполнено при финансовой поддержке РФФИ в рамках научного проекта №16-3400106 мол_а.

\section{Введение}

Потенциал биологической активности лекарственных растений определяется содержанием в них комплекса веществ, которые оказывают целебное действие. Исследование биохимического разнообразия растений помогает оценить перспективность растений как носителей биологически активных веществ, а также вносит дополнительные сведения в систематику спорных таксонов $[1,2]$.

Виды рода Spiraea L. (спирея) представляют значительный интерес как растения, используемые в народной медицине и имеющие большой ресурсный потенциал. В спиреях обнаружены фенольные соединения с высокой биологической активностью: флавонолы, флавоны, флаваны, фенолкарбоновые кислоты, сапонины и др. [3-5]. S. betulifolia Pall. (спирея березолистная) является одной из малоизученных спирей на содержание вторичных метаболитов и проявление биологической активности. Известно, что спирея березолистная проявляет антимикробную активность, на Чукотке используется как суррогат чая, а также она имеет кормовое значение. Сок листьев проявляет фитонцидную активность $[3,6]$. Выявлена антиоксидантная активность водных и водно-этанольных экстрактов из листьев и соцветий спиреи [7].

Метод высокоэффективной жидкостной хроматографии (ВЭЖХ) с успехом применяется в изучении состава и содержания различных групп биологически активных веществ в экстрактах растений, в том числе и фенольных соединений [8]. Это высокоточный и чувствительный метод, позволяющий исследовать вещества в смеси. На процесс экстрагирования веществ из растительного сырья влияют различные факторы: степень измельчения сырья, температура, продолжительность процесса экстракции, природа экстрагента и др. [9]. Поэтому для каждого растительного объекта необходим подбор условий экстракции для более полного извлечения фенольных соединений методами ВЭЖХ.

Костикова Вера Андреевна - кандидат биологических наук, младший научный сотрудник,

e-mail: serebryakova-va@yandex.ru
Цель настоящей работы - выбор оптимальных условий экстракции фенольных соединений из листьев S. betulifolia для их исследования методом ВЭЖХ. 


\section{Объекты и материаль}

Объектом для исследования фенольных соединений послужила S. betulifolia. Материал был собран автором в Еврейской автономной области, в окрестностях п. Облучье в фазе образования плодов в августе 2013 г. Для исследования фенольных соединений с 15 особей равномерно по всей кроне куста брали по десять листьев и высушивали их на воздухе в затененном месте. После сушки сырье измельчали до 2-3 мм, перемешивали и отбирали среднюю пробу. Анализ проводили в двух повторностях.

При планировании эксперимента в качестве переменных факторов были выбраны концентрация экстрагента и масса навески сырья.

Хроматографическое изучение фенольных соединений проводили в водном и водно-этанольных (20, $40,50,60,70,80$ и 96\%) извлечениях из листьев $S$. betulifolia, полученных экстракцией на водяной бане. Точную навеску $(0,5$ г) измельченного воздушно-сухого материала экстрагировали дважды: сначала 30 мл экстрагента в течение 30 мин, затем 20 мл экстрагента в течение 20 мин. После фильтрации остаток в колбе и на фильтре промывали 5 мл 70\% спирта. Мерным цилиндром замеряли объем полученного объединенного экстракта, который составил 40-50 мл [2].

При исследовании влияния массы навески сырья $(0,1,0,2,0,4,0,6,0,8,1$ г) на состав фенольных соединений S. betulifolia использовали экстракты, полученные с применением $40 \%$ водно-этанольного раствора.

После проведения анализа на ВЭЖХ экстракты концентрировали в вытяжном шкафу («Ezermester») в фарфоровых чашечках до 10-15 мл (точный объем) и снова анализировали. Об эффективности экстракции судили по качественному составу фенольных веществ на ВЭЖХ-хроматограммах.

1 мл экстракта разбавляли бидистиллированной водой до 5 мл и пропускали через концентрирующий патрон Диапак С16 (ЗАО «БиоХимМак») для освобождения от примесей гидрофильной природы. Вещества смывали с патрона небольшим количеством (3 мл) этанола соответствующей концентрации (водный экстракт смывали 40\% водно-этанольным раствором), а затем 2 мл 96\% этанола. Объединенный элюат пропускали через мембранный фильтр с диаметром пор 0,45 мкм.

Анализ фенольных соединений, содержащихся в элюате, проводили на аналитической ВЭЖХсистеме, состоящей из жидкостного хроматографа «Agilent 1200» с диодноматричным детектором и системой для сбора и обработки хроматографических данных ChemStation. Разделение проводили на колонке Zorbax SB-C18, размером 4,6×150 мм, с диаметром частиц 5 мкм, применив градиентный режим элюирования. В подвижной фазе содержание метанола в водном растворе ортофосфорной кислоты $(0,1 \%)$ изменялось от 50 до $52 \%$ за 56 мин. Скорость потока элюента 1 мл/мин. Температура колонки $26^{\circ} \mathrm{C}$. Объем вводимой пробы 10 мкл. Детектирование осуществляли при длине волны $\lambda=360$ нм [8].

Для приготовления подвижных фаз использовали метиловый спирт (ос.ч.), ортофосфорную кислоту (ос.ч.), бидистиллированную воду. Вещества идентифицировали методом сопоставления времени удерживания пиков веществ на хроматограммах анализируемых образцов с временами удерживания пиков стандартных образцов и УФ спектров. Для приготовления стандартных образцов использовали хлорогеновую, $n$-кумаровую кислоты, кверцетин, кемпферол («Sigma-Aldrich»), рутин гиперозид, авикулярин, астрагалин («Fluka») и дигидрокверцетин («Austrowaren»).

\section{Результаты и обсуждение}

Согласно литературным данным в листьях S. betulifolia содержатся флавонолы - кемпферол, кверцетин, гликозиды кверцетина - рутин и гиперозид, гликозид кемпферола - астрагалин [7]. В результате исследования фенольных соединений, содержащихся в водном и водно-этанольных экстрактах из листьев S. betulifolia, обнаружено 25 соединений фенольной природы. Из них идентифицированы две фенолкарбоновые кислоты - хлорогеновая кислота и $n$-кумаровая, один флаванонол - дигидрокверцетин и 6 флавонолов - агликоны кверцетин и кемпферол, гликозиды кверцетина рутин, гиперозид и гликозид кемпферола астрагалин (рис., табл.). Основными веществами в экстрактах листьев S. betulifolia являются гиперозид, рутин, авикулярин и неидентифицированные соединения № $6,17,20,21,23$ и 24. Для них получены спектральные характеристики, кроме соединений № 21 и 24 (рис., табл.). В таблице приведены вещества, для которых нами получена спектральная характеристика. Согласно УФ-спектрам можно предположить, что соединения № 6, 17, 20 и 23 относятся к классу оксибензойных кислот, флавонов или флавонолов [10].

Основные вещества, содержащиеся в листьях $S$. betulifolia, можно обнаружить во всех исследованных экстрактах. Максимальное количество фенольных соединений, содержащихся в листьях S. Betulifolia, - 22 соединения - выявлено в водном экстракте, а также в экстрактах, полученных с использованием 20 и 
40\% водно-этанольных растворов. В экстрактах, полученных с использованием раствора этанола 50 , 60 и 70\%, обнаружено 18 , в $80 \%$ - 15 и в 96\% - 10 соединений. При концентрировании экстрактов в водном, водно-этанольных экстрактах (20 и 40\%) было обнаружено еще три минорных компонента, в результате выявлено 25 соединений; при концентрировании экстрактов, полученных с использованием водноэтанольных растворов 50, 60 и 70\% также установлено 25 веществ; в концентрированных экстрактах, полученных на этаноле 80 и 96\%, состав фенольных соединений не изменился.

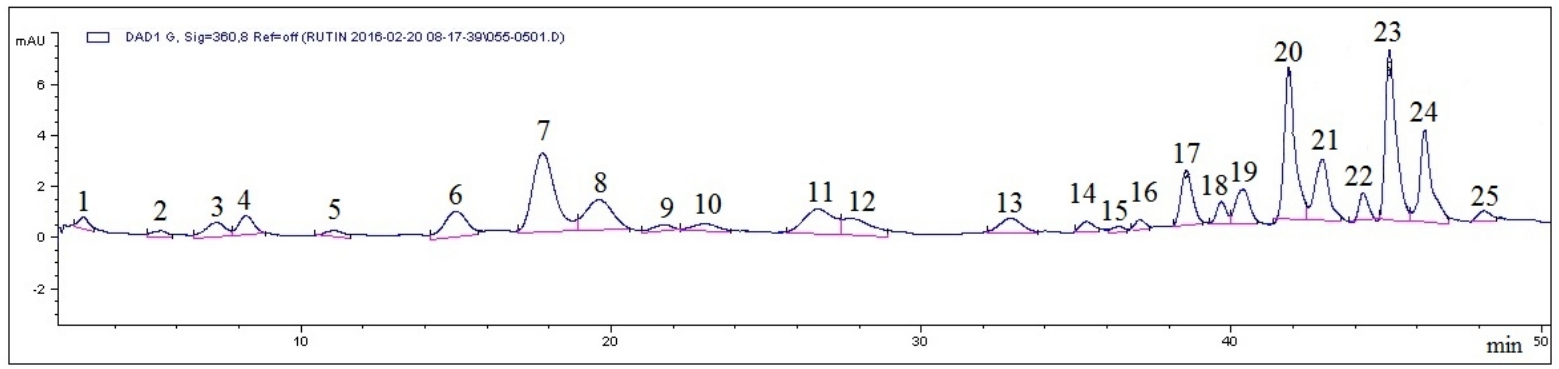

Хроматограмма концентрированного экстракта, полученного с использованием 40 \% водно-этанольного раствора из листьев растений S. betulifolia при 360 нм. По оси абсцисс - время удерживания, мин; по оси ординат - оптическая плотность

Характеристика фенольных соединений, обнаруженных в экстрактах из листьев Spiraea betulifolia

\begin{tabular}{c|c|c|c}
\hline № пика & Соединение & Время удерживания $\left(\mathrm{t}_{\mathrm{R}}\right)$, мин & Спектральная характеристика $\lambda_{\max }$, нм \\
\hline 1 & хлорогеновая кислота & 3,2 & 244,300 пл, 330 \\
3 & n-кумаровая кислота & 7,9 & 226,293 пл, 320 \\
4 & дигидрокверцетин & 8,5 & 290 \\
6 & - & 15,0 & 250,265 пл, 355 \\
7 & гиперозид & 18,0 & 255,268 пл.,355 \\
8 & ругин & 20,0 & 256,358 \\
11 & авикулярин & 28,4 & 260,270 пл, 360 \\
13 & астрагалин & 32,3 & 265,300 пл., 350 \\
17 & - & 38,4 & 265,355 \\
19 & кверцетин & 40,6 & 255,372 \\
20 & - & 42,1 & 255,355 \\
23 & - & 45,7 & 260,350 \\
25 & кемпферол & 47,9 & $225,266,370$ \\
\hline
\end{tabular}

Примечание. «-»- вещество не идентифицировано.

При изучении зависимости состава фенольных соединений в листьях S. betulifolia от массы навески использовали экстракты, полученные с использованием 40\% водно-этанольного раствора. Наиболее полный состав соединений обнаружен в экстрактах с массой навески 0,5, 0,6, 0,8 и 1 г (25 соединений). С массой навески 0,1 г выявлено 16 соединений; 0,2 г - 20 соединений; 0,4 г- 23 соединения. При концентрировании экстрактов выявлено, что все анализируемые экстракты содержат 25 веществ фенольной природы.

Таким образом, подобраны оптимальные условия экстракции для проведения ВЭЖХ анализа, позволяющие извлечь максимальное количество фенольных соединений, содержащихся в листьях растений рода Spiraea. Таковыми являются предварительно концентрированные экстракты, полученные из навески 0,11 г с использованием 40-70\% водно-этанольного раствора.

В листьях S. betulifolia методами ВЭЖХ определено 25 соединений фенольной природы, из которых идентифицированы хлорогеновая и $n$-кумаровая кислоты, дигидрокверцетин, кверцетин, кемпферол, рутин, гиперозид и астрагалин.

\section{Список литературы}

1. Harborne J.B. Comparative Biochemistry of the Flavonoids. New York, 1967. 383 p.

2. Высочина Г.И. Фенольные соединения в систематике и филогении семейства гречишных. Новосибирск, 2004. $240 \mathrm{c.}$

3. Растительные ресурсы СССР: Цветковые растения, их химический состав, использование; Семейства Hydraginaceae - Haloragaceae. Л., 1987. С. 99-101. 
4. Mughal U.R., Mehmood R., Malik A., Alia B., Tareen R.B. Flavonoid Constituents from Spiraea brahuica // Helvetica Chimica Acta. 2012. Vol. 95. Pp. 100-105.

5. Hiradate S., Morita S., Sugie H., Fuji Y., Harada J. Phytotoxic cis-cinnamoyl glucosides from Spiraea thunbergii // Phytochem. 2004. Vol. 65. Pp. 731-739.

6. Киселева Т.И., Чиндяева Л.Н., Цыбуля Н.В. Биологические особенности и антимикробные свойства видов рода Spiraea L. в Новосибирске // Вестник Иркутской государственной сельскохозяйственной академии. 2011. №44-1. C. 65-72.

7. Костикова В.А. Спиреи (Spiraea L.) Дальнего Востока России: изменчивость, хемотаксономия, использование : автореф. дис. ... канд. биолог. наук. Новосибирск, 2013. 16 с.

8. Храмова Е.П., Комаревцева Е.К. Изменчивость флавоноидного состава листьев Potentilla fruticosa (Rosaceae) разных возрастных состояний в условиях Горного Алтая // Растительные ресурсы. 2008. №3. С. 96-102.

9. Минина С.А., Громова Н.А. Теория и аппаратурное оформление процесса экстракции. Л., 1985. 40 с.

10. Запрометов М.Н. Основы биохимии фенольных соединений: учебное пособие. М., 1974. 213 с.

Поступило в редакияию 19 июля 2016 г.

После переработки 16 ноября 2016 г.

Kostikova V.A. DETERMINATION OF OPTIMUM CONDITIONS OF EXTRACTION FOR INVESTIGATION OF COMPOSITION OF PHENOLIC COMPOUNDS SPIRAEA BETULIFOLIA PALL. BY HPLC METHOD

Central Siberian Botanical Garden SB RAS, ul. Zolotodolinskaya, 101, Novosibirsk 630090 (Russia),

e-mail: serebryakova-va@yandex.ru

Studies on optimizing the conditions of extraction of phenolic compounds from the leaves of Spiraea betulifolia Pall. for further chemotaxonomic and phytochemical research by high performance liquid chromatography (HPLC) are conducted. Concentration of extraction agent (water and water - ethanol 20,40,50,60,70,80 and 96\% extraction) and the mass of raw sample $(0,1,0,2,0,4,0,6,0,8$ and $1 \mathrm{~g})$ were selected as variable factors. Qualitative composition of phenolic compounds on HPLC - chromatograms served as indicator of efficiency of extraction. Studies have shown that concentrated $40-70 \%$ waterethanol extracts with the mass of raw sample $0,1-1 \mathrm{~g}$ are more suitable for the detection of the whole of composition of phenolic compounds present in the leaves of $S$. betulifolia by HPLC method. Twenty five compounds found in the leaves of $S$. betulifolia by HPLC method. Nine substances were identified as chlorogenic and $n$-coumaric acid, dihydroquercetin, quercetin, kaempferol, rutin, giperozid, avikulyarin and astragalin.

Keywords: Spiraea betulifolia, extraction, phenolic compounds, HPLC.

\section{References}

1. Harborne J.B. Comparative Biochemistry of the Flavonoids, New York, 1967, 383 p.

2. Vysochina G.I. Fenol'nye soedineniia v sistematike i filogenii semeistva grechishnykh. [Phenolic compounds in systematics and phylogeny of the family Polygonaceae]. Novosibirsk, 2004, 240 p. (in Russ.).

3. Rastitel'nye resursy SSSR: Tsvetkovye rasteniia, ikh khimicheskii sostav, ispol'zovanie; Semeistva Hy-draginaceae Haloragaceae. [Plant resources of the USSR: Flowering plants, their chemical composition, the use of; Family Hydraginaceae - Haloragaceae]. Leningrad, 1987, pp. 99-101. (in Russ.).

4. Mughal U.R., Mehmood R., Malik A., Alia B., Tareen R.B. Helvetica Chimica Acta, 2012, vol. 95, pp. $100-105$.

5. Hiradate S., Morita S., Sugie H., Fuji Y., Harada J. Phytochem, 2004, vol. 65, pp. 731-739.

6. Kiseleva T.I., Chindiaeva L.N., Tsybulia N.V. Vestnik Irkutskoi gosudarstvennoi sel'skokhoziaistvennoi akademii, 2011, no. 44-1, pp. 65-72. (in Russ.).

7. Kostikova V.A. Spirei (Spiraea L.) Dal'nego Vostoka Rossii: izmenchivost', khemotaksonomiia, ispol'zova-nie: avtoref. dis. ... kand. biolog. nauk. [Spiraea (Spiraea L.) Far East Russia: variability chemotaxonomy, use: Abstract of Dis. ... Cand. biological Sciences]. Novosibirsk, 2013, 16 p. (in Russ.).

8. Khramova E.P., Komarevtseva E.K. Rastitel'nye resursy, 2008, no. 3, pp. 96-102. (in Russ.).

9. Minina S.A., Gromova H.A. Teoriia i apparaturnoe oformlenie protsessa ekstraktsii. [Theory and hardware registration of extraction process]. Leningrad, 1985, 40 p. (in Russ.).

10. Zaprometov M.N. Osnovy biokhimii fenol'nykh soedinenii: uchebnoe posobie dlia biol. spetsial'nykh universitetov. [Fundamentals of Biochemistry of phenolic compounds: a manual for biol. special universities]. Moscow, 1974, 213 p. (in Russ.). 